\title{
Histórico de criação da Unidade de Conservação Refúgio de Vida Silvestre Serra da
}

\section{Fortaleza do Sul de Goiás}

\author{
History of the creation of the Conservation Unit Refúgio de Vida Silvestre Serra da Fortaleza in the \\ South of Goiás
}

Historia de creación de la Unidad de Conservación Refúgio de Vida Silvestre Serra da Fortaleza en el Sur de Goiás

\author{
Isa Lucia de Morais \\ ORCID: https://orcid.org/0000-0001-8748-9723 \\ Universidade Estadual de Goiás, Brasil \\ E-mail: isamorais1@gmail.com \\ Quézia Peres da Silva \\ ORCID: https://orcid.org/0000-0003-0081-7179 \\ Universidade Estadual de Goiás, Brasil \\ E-mail: queziatdb_2011@ hotmail.com \\ Poliana Ribeiro Dourado \\ ORCID: https://orcid.org/0000-0001-7885-9905 \\ Universidade Estadual de Goiás, Brasil \\ E-mail: polydourado@hotmail.com \\ Raoni Ribeiro Guedes Fonseca Costa \\ ORCID: https://orcid.org/0000-0003-2575-8582 \\ Universidade Estadual de Goiás, Brasil \\ E-mail: raoniueg@hotmail.com
}

\begin{abstract}
Resumo
As unidades de conservação são espaços importantes, para a preservação da biodiversidade de um determinado local, em especial nos mais ameaçados como o domínio fitogeográfico do Cerrado. O histórico de criação de uma unidade de conservação, além de ser essencial e de direito dos cidadãos de determinada região, também pode servir como subsídio e apoio para outras regiões utilizarem como modelo. Neste sentido, esta pesquisa objetivou descrever o processo de criação da Unidade de Conservação Refúgio de Vida Silvestre Serra da Fortaleza, em Quirinópolis, Goiás. O levantamento dos dados foi realizado com subsídio em documentos disponibilizados pela Secretaria Municipal do Meio Ambiente de Quirinópolis e entrevistas. A criação da UC RVSSF foi devida a um conjunto de ações mobilizadas por um grupo de proprietários de imóveis rurais ao destinar a reserva legal conjuntamente para uma área como reserva legal extra propriedade; pela contínua ação dos servidores do Ministério Público junto ao Poder Executivo para a efetivação do compromisso firmado no TAC e a contribuição de pesquisadores da UEG, Câmpus Sudoeste, Sede Quirinópolis, juntamente com os servidores da Secretaria Municipal de Meio Ambiente e Recursos Hídricos. Os procedimentos para criação seguiram os preceitos subsidiados pela legislação ambiental vigente. Esta unidade consiste em uma importante estratégia em prol de assegurar a manutenção de uma rica biodiversidade de um dos patrimônios ecológicos mais ameaçados do mundo. A relevância de sua criação se torna ainda maior em razão de ser o primeiro espaço de conservação de Goiás na categoria de Refúgio de Vida Silvestre.

Palavras-chave: Área de preservação ambiental; Biodiversidade; Cerrado; Georreferenciamento de imóvel rural; Reserva legal extra-propriedade.
\end{abstract}

\begin{abstract}
Conservation units are important spaces for the preservation of biodiversity in a given location, especially in the most threatened, such as the phytogeographic domain of the Cerrado. The history of the creation of a conservation unit, in addition to being essential and a right of citizens in a given region, can also serve as a subsidy and support for other regions to use as a model. In this sense, this research aimed to describe the process of creation of the Wildlife Refuge Conservation Unit Serra da Fortaleza, in Quirinópolis, Goiás. The data survey was carried out with subsidy in documents made available by the Municipal Environment Department of Quirinópolis and interviews. The creation of the UC RVSSF was due to a set of actions mobilized by a group of rural property owners when allocating the legal reserve jointly to an area as an extra-property legal reserve; for the continuous action of the Public Ministry's servers with the Executive Power to carry out the commitment signed in the TAC and the contribution of researchers from UEG, Câmpus Sudoeste, Sede Quirinópolis, together with servers from the Municipal Secretariat for the Environment and Water Resources. The creation procedures followed the precepts subsidized by the current environmental
\end{abstract}


legislation. This unit is an important strategy to ensure the maintenance of a rich biodiversity of one of the most threatened ecological heritages in the world. The relevance of its creation becomes even greater as it is the first conservation space in Goiás in the category of Wildlife Refuge.

Keywords: Environmental preservation area; Biodiversity; Cerrado; Rural property georeferencing; Extra-property legal reservation.

\section{Resumen}

Las unidades de conservación son espacios importantes para la preservación de la biodiversidad en un lugar determinado, especialmente en los más amenazados, como el dominio fitogeográfico del Cerrado. La historia de la creación de una unidad de conservación, además de ser esencial y un derecho de los ciudadanos en una región determinada, también puede servir como un subsidio y apoyo para que otras regiones la utilicen como modelo. En este sentido, esta investigación tuvo como objetivo describir el proceso de creación de la Unidad de Conservación del Refugio de Vida Silvestre Serra da Fortaleza, en Quirinópolis, Goiás, el levantamiento de datos se realizó con subsidio en documentos puestos a disposición por el Departamento Municipal de Medio Ambiente de Quirinópolis y entrevistas. La creación de la UC RVSSF se debió a un conjunto de acciones movilizadas por un grupo de propietarios rurales al destinar la reserva legal de manera conjunta a un área como reserva legal extrapropiedad; por la acción continua de los servidores del Ministerio Público con el Poder Ejecutivo para llevar a cabo el compromiso suscrito en el TAC y el aporte de investigadores de la UEG, Câmpus Sudoeste, Sede Quirinópolis, junto con servidores de la Secretaría Municipal de Medio Ambiente y Recursos Hídricos. Los procedimientos de creación siguieron los preceptos subvencionados por la legislación ambiental vigente. Esta unidad es una estrategia importante para asegurar el mantenimiento de una rica biodiversidad de uno de los patrimonios ecológicos más amenazados del mundo. La relevancia de su creación se vuelve aún mayor al ser el primer espacio de conservación en Goiás en la categoría de Refugio de Vida Silvestre.

Palabras clave: Área de preservación ambiental; Biodiversidad; Cerrado; Georreferenciación de la propiedad rural; Reserva legal extrapropiedad.

\section{Introdução}

O planeta encontra-se numa crise de biodiversidade com a perda acelerada de espécies e de ecossistemas inteiros. Neste viés, para que haja permanência dos remanescentes naturais e da diversidade biológica associada é necessário um conjunto de práticas que vão desde a preservação integral das comunidades bióticas estáveis ao manejo de ecossistemas modificados por ações antrópicas (Ganem, 2010; Salomão et al., 2020; Viana et al., 2020).

Diante desta realidade, as Unidades de Conservação (UC's) são ferramentas importantes, haja vista que viabilizam o estudo e preservação da biodiversidade de um bioma, promove proteção ambiental e concilia o uso dos recursos naturais com o desenvolvimento econômico, social e turístico de uma região (Garbelini, 2011; Rocha et al., 2019; Moraes et al., 2020). Tais áreas de conservação minimizam os problemas oriundos da 'crise ambiental' e melhoram a qualidade de vida da biota integrada direta e indiretamente a elas (Simões, 2008; Rocha et al., 2019).

A criação das Unidades de Conservação no Brasil é subsidiada pela Lei Federal nº 9.985/2000 (Brasil, 2000) e o Decreto Federal no 4.340/2002 (Brasil, 2002). Essa legislação estabelece que a criação das UC's ocorra por meio de ato do Poder Público (Poder Executivo e Poder Legislativo) após a realização de estudos técnicos da importância ecológica dos espaços propostos e, quando necessário, consulta à população. Em consonância com a legislação federal, no Estado de Goiás a Lei Estadual no 12.247/2002 (Goiás, 2002) e o Decreto Estadual nº 5.806/2003 (Goiás, 2003) estabelecem a criação do Sistema Estadual de Unidades de Conservação (SEUC). Por essa legislação estadual a Unidade de Conservação é definida como o espaço territorial e seus recursos ambientais, incluindo as águas jurisdicionais, com características naturais relevantes, legalmente instituída pelo Poder Público, com objetivos de conservação e limites definidos, sob regime especial de administração, à qual se aplicam garantias adequadas de proteção (Goiás, 2002).

O estado de Goiás é uma das unidades da federação brasileira com menor índice de áreas legalmente protegidas que possam contribuir para assegurar a conservação da biodiversidade, do meio abiótico e para a manutenção do equilíbrio ecológico. As UC's Estaduais correspondiam, até 2012, a aproximadamente 4\% do território goiano, dos quais quase 10\% eram de Proteção Integral (Salmona et al., 2014). Em 2013 foram realizadas consultas públicas para discutir a criação de três 
novos parques estaduais no nordeste de Goiás: São Bartolomeu (área nos municípios de Alto Paraíso de Goiás, Cavalcante e Nova Roma), Serra da Prata (no município de Monte Alegre de Goiás) e Rio São Félix (no município de Cavalcante). A criação desses parques até o momento não foi concretizada. Porém, em 2017 foi criada, pelo Decreto Estadual n 9.023/2017, a Estação Ecológica da Chapada de Nova Roma (ESEC CNR), sendo a primeira Estação Ecológica do estado de Goiás (Goiás, 2017).

Atualmente, Goiás tem, de acordo com informações da Secretaria de Estado de Meio Ambiente e Desenvolvimento Sustentável (Semad, 2021), 24 UC's, sendo na categoria de Unidades de Proteção Integral, 13 Parques Estaduais (Parques Estaduais Águas Lindas (PEAL); Águas do Paraíso (PEAP); Altamiro de Moura Pacheco (PEAMP); do Araguaia (PEA); do João Leite (PEJol); da Mata Atlântica (PEMA); de Paraúna (PEPa); dos Pirineus (PEP); da Serra de Caldas Novas (PESCaN); da Serra Dourada (PESD); da Serra de Jaraguá (PESJ); Telma Ortegal (PETO) e de Terra Ronca (PETeR)) e uma Estação Ecológica (da Chapada de Nova Roma (ESEC CNR)); e na categoria de Unidades de Uso Sustentável 8 Áreas de Proteção Ambiental (da Serra Geral de Goiás (APA Serra Geral); de Pouso Alto (APA Pouso Alto); da Serra das Galés e da Portaria (APA Serra das Galés); João Leite (APA João Leite); do Encantado (APA Encantado); Dr. Sulivan Silvestre (APA Serra Dourada); dos Pireneus (APA Pireneus); da Serra da Jibóia (APA Serra da Jibóia)); uma Área de Relevante Interesse Ecológico (Águas de São João (ARIE São João)) e uma Floresta Estadual (do Araguaia (FLOE Araguaia)).

Além destas unidades de conservação, o Estado de Goiás conta também com dois parques (Parque Nacional das Emas e Parque Nacional da Chapada dos Veadeiros) e seis unidades de conservação de uso sustentável de domínio federal, além de 40 Reservas Particulares do Patrimônio Natural (RPPN) e 17 Parques Municipais.

Segundo Sano et al. (2007) até 2002 restavam em Goiás 44\% da cobertura vegetal nativa original. E grande parte desta vegetação encontra-se concentrada no norte goiano, justamente por esta região abranger áreas menos aptas à agropecuária. No tocante à paisagem goiana quanto mais ao sul do estado, mais os fragmentos remanescentes de Cerrado tendem a ser menores e mais escassos (Salmona et al., 2014), devido à intensificação das atividades agropecuárias. Nesse sentido, a criação de novas unidades de conservação, especialmente as de proteção integral, representa um acréscimo importante à porção de nossos ecossistemas como áreas protegidas, garantindo a conservação e ou preservação de parcela representativa da biodiversidade brasileira, principalmente do domínio fitogeográfico do Cerrado.

Em Quirinópolis, município localizado no sul goiano, restam fragmentos, geralmente pequenos e isolados, principalmente das fitofisionomias de cerradão, mata seca semidecídua, cerrado sentido restrito, mata de galeria, mata ciliar, vereda, buritizal e campo limpo úmido (Morais et al., 2017; Morillo et al., 2017; Bueno et al., 2019). Existem também pouquíssimos fragmentos maiores, os quais devem ser conservados, haja vista que estes subsidiam um conjunto de condições favoráveis para manutenção da biodiversidade ao longo do tempo (Morais et al., 2017; Morais et al., 2021).

Neste contexto, em 2015 foi criada a primeira Unidade de Conservação em Quirinópolis, com o nome de Refúgio de Vida Silvestre Serra da Fortaleza (RVSSF) (Morais et al., 2017). De acordo com o Sistema Nacional de Unidades de Conservação (SNUC) - Art. $7^{\circ}$, da Lei 9.985/2000 - as UC's na categoria Refúgio de Vida Silvestre são Unidades de Conservação de Proteção Integral (Brasil, 2000). Nas UC's de Proteção Integral a conservação da natureza é o principal objetivo. Diante disso, as regras e normas são mais restritivas, sendo permitido apenas o uso indireto dos recursos naturais. Esse uso indireto não envolve consumo, coleta ou dano aos recursos naturais e abrange atividades como visitação, recreação em contato com a natureza, turismo ecológico, pesquisa científica, educação e interpretação ambiental (ICMBio, 2009).

O histórico de criação de uma UC, além de ser essencial e de direito dos cidadãos de determinada região, também pode servir como subsídio e apoio para outras regiões se encorajarem e desenvolver um projeto para criar mais UC's. Neste sentido, esta pesquisa objetivou descrever o processo de criação da UC RVSSF, Quirinópolis, Goiás. 


\section{Material e Métodos}

\section{Área de estudo}

A UC RVSSF (18¹4'50.5" S, 5040'54.1" O) localiza-se ao sul do estado de Goiás, na porção nordeste da microrregião de Quirinópolis, distando cerca de $50 \mathrm{~km}$ da área urbana de Quirinópolis. O município encontra-se inserido no domínio fitogeográfico do Cerrado, na Microrregião 18 e Mesorregião Sul Goiano e apresenta área de $3.792 \mathrm{~km}^{2}$ e 50.065 habitantes (IBGE, 2019; Morais et al., 2021) (Figura 1). A temperatura média anual é de $21^{\circ} \mathrm{C}$, com pouca variação nas médias mensais. A pluviosidade média é de $1.400 \mathrm{~mm} / \mathrm{ano}$, irregularmente distribuída no decorrer do ano, com maior incidência nos meses de novembro a abril (Galinkin, 2003).

Figura 1. Mapa da Unidade de Conservação Refúgio de Vida Silvestre Serra da Fortaleza, Quirinópolis, sul de Goiás.

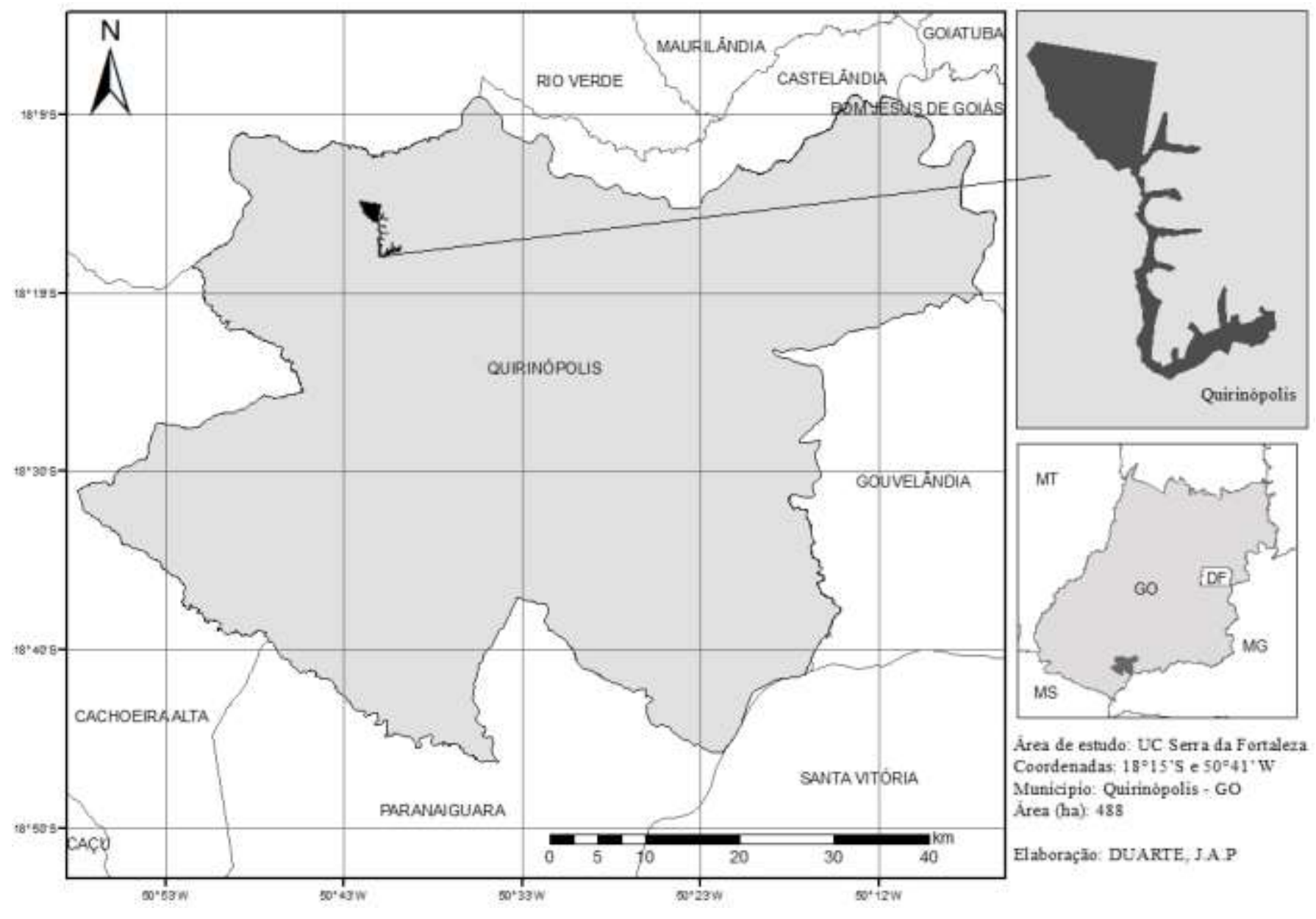

Fonte: Autores.

No município de Quirinópolis foram implantadas duas usinas pertencentes aos maiores grupos sucroenergéticos do Brasil: uma do Grupo SJC Bioenergia (uma Joint Venture entre a Cargill e o grupo São João), a Usina São Francisco, e a outra, do Grupo São Martinho, conhecida como Usina Boa Vista. Essa expansão do setor sucroalcooleiro é composta, na maior parte, pela produção de açúcar e álcool, com a possibilidade de cogeração de energia elétrica que é utilizada no sustento do próprio sistema produtivo. Com isso, houve mudanças socioeconômicas e ambientais em Quirinópolis e região. Vale ressaltar que o sul de Goiás, mesmo antes da implantação do setor sucroalcooleiro, já estava antropizado pelas atividades da pecuária e agricultura, com a existência de poucos remanescentes de vegetação nativa. 
A Serra da Fortaleza faz parte da Serra da Confusão do Rio Preto, sendo esta de formação muito extensa. Assim, trechos da Serra da Confusão do Rio Preto recebem nomes referenciais, de acordo com cada região rural. No caso da Serra da Fortaleza um dos principais motivos do seu nome é o Ribeirão Fortaleza que integra o local (Figura 2, B-C).

Figura 2. Algumas das fitofisionomias da Unidade de Conservação Refúgio de Vida Silvestre Serra da Fortaleza, Quirinópolis, sul de Goiás. A: Floresta seca semidecídua; B-C: mata de galeria que acompanha o Ribeirão Fortaleza; D: Campo sujo úmido na frente e no fundo floresta seca semidecídua.

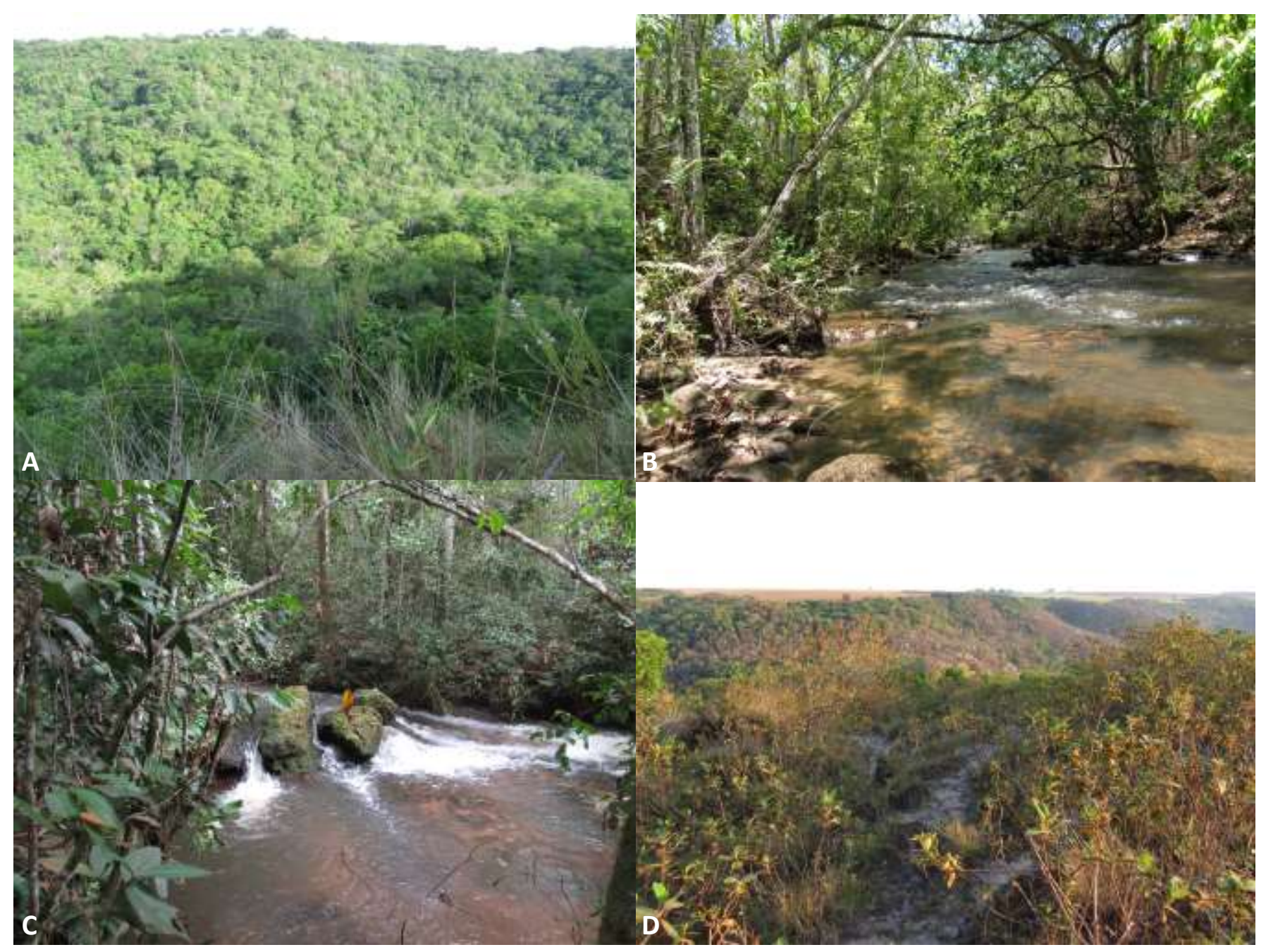

Fonte: Isa Lucia de Morais.

A UC RVSSF tem, aproximadamente, 490 ha sendo constituída por fragmentos de mata seca semidecídua, com transição para vereda e esta para mata de galeria (Figura 2). Os fragmentos estão circundados principalmente por pastagem e cultura anuais, como o milho.

\section{Levantamento dos dados}

O levantamento dos dados do histórico de criação da UC RVSSF foi realizado com subsídio em documentos disponibilizados pela Secretaria Municipal do Meio Ambiente (SEMMA) de Quirinópolis (principalmente o Estudo Técnico de criação da UC RVSSF) e realização de entrevistas. A nossa pesquisa é caracterizada como um estudo de caso, método que utiliza dados qualitativos, coletados a partir de eventos reais, com o objetivo de explicar, explorar ou descrever fenômenos atuais inseridos em seu próprio contexto (Yin, 2009). Assim, a pesquisa foi subsidiada por uma abordagem descritiva e com 
metodologia propostas por Pereira et al. (2018), com o procedimento de coleta de dados mediante aplicação de entrevistas semiestruturadas. Esse tipo de entrevista está estruturado em um assunto sobre o qual há um roteiro com perguntas principais, complementadas por outras questões inerentes às circunstâncias momentâneas à entrevista. Dessa forma, permite-se o emergir de informações de forma mais livre e as respostas não estão condicionadas a uma padronização de alternativas (Manzini, 1991).

Para realização das entrevistas foi necessário obter o consentimento de cada um dos entrevistados. Para tal, estes foram informados sobre os objetivos e importância desta pesquisa e a garantia do sigilo como premissa ética entre pesquisador e entrevistados. O consentimento dos participantes foi formalizado através de Termo de Consentimento, conforme exigências da Resolução no: 446/12, de 12 de dezembro de 2012, do Conselho Nacional de Saúde do Ministério da Saúde, a qual estabelece que se tratando da realização de pesquisa com seres humanos, o indivíduo a ser pesquisado deve conhecer os objetivos e o modo como os dados serão utilizados (CNS, 2012). O inciso V do parágrafo único da Resolução no 510 , de 07 de abril de 2016, estabelece que não serão registradas nem avaliadas pelo sistema CEP/CONEP (Comitês de Ética em Pesquisa/Comissão Nacional de Ética em Pesquisa) pesquisa com bancos de dados, cujas informações são agregadas, sem possibilidade de identificação individual (CNS, 2016). Por considerarmos que os dados da presente pesquisa se enquadram neste item não houve a submissão deste estudo no Comitê de Ética em Pesquisa com seres humanos.

Foram entrevistadas cinco pessoas envolvidas no processo de criação da UC RVSSF. As entrevistas ocorreram de junho a julho de 2018. Para manter o anonimato de cada entrevistado eles foram numerados de 1 a 5 , e os números foram usados para indicar a origem da informação. O questionário foi enviado por e-mail, assim como as respectivas respostas, com exceção de um entrevistado, que preferiu utilizar um gravador de voz. O questionário abrangeu perguntas específicas para cada entrevistado, conforme seu conhecimento referente à UC RVSSF ou participação de sua criação (Quadro 1). A percepção acerca da necessidade de ter diferentes questionários, específico à cada entrevistado, foi subsidiada pelo Estudo Técnico de Criação da UC RVSSF, no qual é possível compreender como se deu a participação de cada entrevistado. 
Quadro 1. Questionários usados nas entrevistadas aos envolvidos no processo de criação da UC RVSSF, em Quirinópolis, Goiás.

\begin{tabular}{|c|c|}
\hline Entrevistados & Questionário \\
\hline 1 & $\begin{array}{l}\text { 1. Quando e como surgiu a ideia de criação de uma Unidade de Conservação Ambiental em Quirinópolis? } \\
\text { 2. Sabemos que em } 2006 \text { a ONG Associação Galeatus sugeriu a criação de uma Unidade de Conservação no município como forma de } \\
\text { compensação da implantação de duas usinas na cidade. Esse fato teve alguma influência para que a Prefeitura e o Ministério Público } \\
\text { tomassem iniciativa para a criação da Unidade de Conservação? } \\
\text { 3. Quais os aspectos que indicaram a necessidade e importância para a criação dessa Unidade de Conservação? } \\
\text { 4. Houve outro(s) motivo(s) para a criação dessa Unidade de Conservação além do objetivo de conservar a biodiversidade local? } \\
\text { 5. Quais os motivos envolvidos na escolha do local que hoje é a Unidade de Conservação? } \\
\text { 6. Essa área tinha mais de um dono? E hoje, toda a área é da prefeitura? } \\
\text { 7. Como foi feita a organização e regularização das APP's que hoje é a área da Unidade de Conservação? } \\
\text { 8. Quais foram as etapas judiciais envolvidas na criação da Unidade de Conservação? } \\
\text { 9. Houve dificuldades para a criação da Unidade de Conservação? Se sim, quais foram? } \\
\text { 10. Qual a data que foi aprovada a criação da Unidade de Conservação? } \\
\text { 11. A unidade de conservação Serra da Fortaleza tem um Conselho Consultivo? Este conselho gestor já desenvolveu o plano de manejo } \\
\text { depois da criação da Unidade de Conservação? } \\
\text { 12. Já foi criada alguma estrutura física na Unidade de Conservação? } \\
\text { 13. A prefeitura recebe o ICMS Ecológico? Despois da criação dessa Unidade de Conservação, já foram feitas ações no local com a utilização } \\
\text { do ICMS Ecológico? } \\
\text { 14. Qual foi seu envolvimento no processo de criação da Unidade de Conservação? } \\
\text { 15. Em sua opinião, quais os aspectos benéficos da criação dessa Unidade de conservação? }\end{array}$ \\
\hline 2 & $\begin{array}{l}\text { 1. Quando e como surgiu a ideia de criação de uma Unidade de Conservação Ambiental em Quirinópolis? } \\
\text { 2. Quais os aspectos que indicaram a necessidade e importância para a criação dessa Unidade de Conservação? } \\
\text { 3. Quais os motivos envolvidos na escolha do local que hoje é a Unidade de Conservação? } \\
\text { 4. Por que a unidade de conservação recebeu o nome Refúgio de Vida Silvestre Serra da Fortaleza? } \\
\text { 5. Houve dificuldades para a criação da Unidade de Conservação? Se sim, quais foram? } \\
\text { 6. Como foi feito o diagnostico ambiental da área para a criação da Unidade de Conservação? } \\
\text { 7. Qual foi seu envolvimento no processo de criação da Unidade de Conservação? De quais etapas participou? } \\
\text { 8. Em sua opinião, quais os aspectos benéficos da criação dessa Unidade de conservação para Quirinópolis? } \\
\text { 9. Depois da criação da Unidade de Conservação você já desenvolveu alguma pesquisa no local? }\end{array}$ \\
\hline 3 & $\begin{array}{l}\text { 1. Quando e como surgiu a ideia de criação de uma Unidade de Conservação Ambiental em Quirinópolis? } \\
\text { 2. Quais os aspectos que indicaram a necessidade e importância para a criação dessa Unidade de Conservação? } \\
\text { 3. Houve outro (s) motivo (s) para a criação dessa Unidade de Conservação além do objetivo de conservar a biodiversidade local? } \\
\text { 4. Quais os motivos envolvidos na escolha do local que hoje é a Unidade de Conservação? } \\
\text { 5. Essa área tinha mais de um dono? E hoje, toda a área é da prefeitura? } \\
\text { 6. Como foi feita a organização e regularização das APP's que hoje é a área da Unidade de Conservação? } \\
\text { 7. Houve dificuldades para a criação da Unidade de Conservação? Se sim, quais foram? } \\
\text { 8. Porque a unidade de conservação recebeu o nome Refúgio de vida silvestre Serra da Fortaleza? } \\
\text { 9. Como foi feito o diagnostico socioeconômico e fundiário do local para a criação da Unidade de Conservação? } \\
\text { 10. Qual foi seu envolvimento no processo de criação da Unidade de Conservação? }\end{array}$ \\
\hline 4 & $\begin{array}{l}\text { 1. Qual foi seu envolvimento no processo de criação da Unidade de Conservação? De quais etapas participou? } \\
\text { 2. Em sua opinião, quais os aspectos benéficos da criação dessa Unidade de conservação para Quirinópolis? } \\
\text { 3. Como foi feito o diagnostico ambiental da área para a criação da Unidade de Conservação? } \\
\text { 4. Depois da criação da Unidade de Conservação você já desenvolveu alguma pesquisa no local? }\end{array}$ \\
\hline 5 & $\begin{array}{l}\text { 1. A unidade de conservação Serra da Fortaleza tem um Conselho Consultivo? } \\
\text { 2. Qual o prazo que a prefeitura dispõe para elaborar o plano de manejo da Unidade de Conservação? } \\
\text { 3. A área está sendo monitorada pelos funcionários do setor da prefeitura responsável pela Unidade de Conservação? } \\
\text { 4. Qual a importância de ter uma estrutura física na Unidade de Conservação? }\end{array}$ \\
\hline
\end{tabular}

Fonte: Autores.

\section{Resultados e Discussão}

\section{A criação da UC RVSSF}

Em 2006, com a implantação da Usina Boa Vista, do Grupo São Martinho, surgiu a ideia de criar uma UC em Quirinópolis. Naquele momento, os membros da recém-criada Associação Galeatus, Organização Não-Governamental (ONG), preocupados com o impacto ambiental oriundo das atividades sucroalcooleiras no município, pleiteou, no momento da audiência pública para a instalação da referida usina, que a destinação da compensação ambiental fosse para a criação de uma UC no município.

Houve também a manifestação por parte da Galeatus de que a UC abrangesse as nascentes do Ribeirão das Pedras (afluente que desagua na Bacia do Paranaíba). Isso se deve ao fato de que esse curso d’água é o manancial de abastecimento da área urbana de Quirinópolis e está severamente ameaçado devido aos inúmeros impactos ambientais que ocorrem na área de preservação permanente que o integra. Para tanto, os membros da Galeatus coletaram cerca de 2.000 assinaturas da 
comunidade quirinopolina. Em seguida, foram até Goiânia e apresentaram a proposta na Agência Ambiental de Goiás, à época, órgão responsável pela gestão ambiental no estado (hoje Semad Goiás (Secretaria Estadual de Meio Ambiente e Desenvolvimento Sustentável de Goiás)). No entanto, o comitê de compensação ambiental desse órgão vetou o pedido justificando a necessidade de regularizar outras UC's já criadas no Estado de Goiás.

Em 2009, um grupo de proprietários rurais procuraram o representante do Sindicato Rural para alterar a reserva legal de seus imóveis para reserva legal extra propriedade. Suas propriedades rurais eram arrendadas para o plantio de cana-deaçúcar. Acontecia que, no registro de suas propriedades constava a porcentagem de reserva legal exigida por lei, mas na prática não. Em muitos dos casos todo o imóvel rural já estava desmatado. Seguindo a lei, a usina sucroalcooleira realizava o plantio nos imóveis destes proprietários, mas não na área destinada a ser a reserva legal, mesmo já desmatada. Insatisfeitos com tal situação, pois, visavam maior lucro financeiro com suas propriedades arrendadas, este grupo de produtores procuraram o representante do Sindicato Rural para alocar a reserva legal de suas propriedades como extra propriedade. De acordo com Lei Lei $\mathrm{n}^{\circ} 18.104$, de 18/07/2013, Art. 25, todo imóvel rural deve manter área com cobertura de vegetação nativa, a título de Reserva Legal, observados os seguintes percentuais mínimos em relação à área de imóveis localizados no Estado de Goiás: 35\%, no imóvel situado em área de cerrado na Amazônia Legal acima do paralelo 13², e, 20\% no imóvel situado nas demais regiões do Estado (os referidos imóveis rurais se enquadram na exigência de $20 \%$ da área total do imóvel serem destinados à Reserva Legal). Ainda segundo esta lei, Art. $5^{\circ}$, III, Reserva Legal consiste na área localizada no interior de uma propriedade ou posse rural com a função de assegurar o uso econômico de modo sustentável dos recursos naturais do imóvel rural, auxiliar na conservação e na reabilitação dos processos ecológicos e promover a conservação da biodiversidade, bem como proporcionar abrigo e proteção à fauna silvestre e à flora nativa; e, no Art. 28 permite-se a compensação ou remanejamento da reserva legal para extra propriedade, mesmo que já tenha sido averbada ou registrada no órgão ambiental competente, desde que seja comprovado o ganho ambiental (Goiás, 2013).

Simultaneamente à mobilização desse grupo de proprietários rurais, o Ministério Público do Estado de Goiás, por intermédio de servidores da $2^{\text {a }}$ Promotoria de Justiça de Quirinópolis, constatou que o Termo de Compromisso de Reserva Legal firmado com estes proprietários acerca da regularização dos $20 \%$ de área de reserva legal, exigidos pelo Código Florestal, não estava sendo cumprido. Para solucionar o problema foi instituído um procedimento extrajudicial, objetivando, por meio de práticas restaurativas, consolidadas no diálogo e no consenso, para realizar o cumprimento dos Termos de Ajustamento de Conduta (TAC'S).

Após várias reuniões para solucionar tal irregularidade, o presidente do Sindicato dos Produtores Rurais de Quirinópolis na época, representando os produtores rurais envolvidos, firmou um acordo com o Ministério Público do Estado de Goiás. Neste ato, foi decidido que parte da área de reserva legal desses proprietários seria alocada fora do município e averbada como áreas de reserva legal extra propriedade. A outra parte seria igualmente alocada como reserva legal extra propriedade, mas, obrigatoriamente dentro do município. Como parte do acordo, as áreas adquiridas deveriam ser destinadas para criação de uma UC de Proteção Integral com o objetivo de compensar a perda ambiental para a região devido à averbação das reservas legais extra propriedades alocadas fora do município.

Assim, em 2011, foi adquirida, coletivamente por esses proprietários, uma área localizada na Serra da Fortaleza, também conhecida como "Serra do Barrilari". Essa área foi, então, destinada para a averbação das reservas legais extra propriedades dentro do munícipio. Com isso, o problema dos TAC's desses proprietários foi sanado junto ao Ministério público local. A área apresenta vegetação nativa extensa e se encontra em ótimo estado de conservação e o imóvel rural do qual essa área fazia parte tinha excedente de vegetação nativa, conforme a legislação ambiental em vigor.

A escolha em alocar essas reservas legais extra propriedades para esta área na Serra da Fortaleza foi devido ao benefício ambiental, haja vista que as reservas legais extra propriedades ficariam no município e contemplariam mananciais 
que abastecem a região, ao invés de serem alocadas para outra região. Além disso, ao alocar todas as extra propriedades para um único local isso resulta em ganho ambiental pelo tamanho maior da área de conservação. Para a conservação da biodiversidade e manutenção do equilíbrio ecológico as áreas de reservas grandes são preferíveis a reservas pequenas (Macarthur \& Wilson, 1963).

Após a aquisição da referida área foi firmado um acordo em regime de condomínio entre todos os envolvidos, averbando-se, de acordo com a matrícula de cada imóvel rural, a destinação daquela área para a implantação de uma área de conservação de proteção integral. Para efetivação da averbação da reserva legal extra propriedade no cartório foi necessário fazer o georreferenciamento da área adquirida. Desde 2001, a demarcação de imóveis rurais no Brasil está pautada na Lei Federal $\mathrm{n}^{\circ}$ 10.267/2001, que, alterando a lei de registros públicos (Lei Federal $\mathrm{n}^{\circ}$ 6.015/1973), estabeleceu o georreferenciamento de imóveis rurais como exigência para a sua escrituração no Livro de Registro Geral (Brasil, 2001). Assim, na referida lei, o Art. $3^{\circ}$, $\S 3^{\circ}$, estabelece que nos casos de desmembramento, parcelamento ou remembramento de imóveis rurais, a identificação do imóvel rural será feita com: indicação do código do imóvel, dos dados constantes do CCIR (Certificado de Cadastro de Imóvel Rural), da denominação e de suas características, confrontações, localização e a área será obtida a partir de memorial descritivo, assinado por profissional habilitado e com a devida Anotação de Responsabilidade Técnica - ART, contendo as coordenadas dos vértices definidores dos limites dos imóveis rurais, georreferenciadas ao Sistema Geodésico Brasileiro e com precisão posicional a ser fixada pelo Incra (Instituto Nacional de Colonização e Reforma Agrária), garantida a isenção de custos financeiros aos proprietários de imóveis rurais cuja somatória da área não exceda a quatro módulos fiscais (Brasil, 2001). Fazer a identificação e caracterização do imóvel rural a partir de tal método, estabelecido por esta lei, é o que se conhece por georreferenciar o imóvel rural, o qual faz uso de tecnologias sofisticadas, como os GPS (Sistema de Posicionamento Global) geodésicos (que promovem a leitura de informações emitidas pelos satélites em órbita e calculam as coordenadas geodésicas - latitude, longitude e altitude), posicionamento pelo RTK (Real Time Kinematic) e drones (Incra, 2018). O georreferenciamento tornou mais eficiente e precisa a gestão territorial. Através desta metodologia evita-se a sobreposição de imóveis, assegura-se a legalidade da propriedade e há redução nas disparidades e lacunas existentes entre a área declarada no registro público do imóvel e a sua situação real in loco. O processo de georreferenciamento da área destinada à averbação das reservas legais extra propriedades só foi concluído em 2014.

Depois desta regularização das reservas legais extra propriedades, iniciou-se o processo de criação da UC. Entretanto, para a criação da UC na modalidade apontada pelos técnicos da Semad Goiás, era indispensável, por força de lei, que o município aderisse ao projeto como parceiro. Iniciou-se, então, outra série de tratativas do Ministério Público junto ao Poder Executivo para sensibilizar o gestor público municipal sobre a importância da criação de uma UC na área adquirida pelos proprietários rurais.

$\mathrm{O}$ ato normativo de criação de uma UC é de competência exclusiva do prefeito municipal. Ademais, não bastaria apenas criar por Lei ou Decreto a UC, pois, o processo de criação da UC envolve recursos financeiros. A Lei do Sistema Nacional de Unidades de Conservação (SNUC) exige estudos técnicos, plano de manejo e outras diligências (MMA, 2019), cujos custos devem contar com previsão orçamentária do Poder Executivo. Assim, diante dos custos em implementar o projeto de criação da UC, os servidores do Ministério Público do Estado de Goiás não obtiveram êxito em conseguir a parceria do município neste momento.

Entretanto, ainda em 2014, o Ministério Público do Estado de Goiás recebeu denúncias acusando o Poder Executivo de Quirinópolis de irregularidades na execução de obras na estrada vicinal da Serra da Confusão do Rio Preto, local conhecido popularmente como "Serra das Antenas". Diante dos fatos, os servidores da $2^{\text {a }}$ Promotoria de Justiça de Quirinópolis acionaram o Núcleo de Apoio Técnico Pericial do Ministério Público. Estes profissionais, após vistoriarem o local, apresentaram o Laudo Técnico Pericial Ambiental n. 128/2014 apontando, às fls. 9, a criação de uma UC de Proteção Integral 
como medida compensatória aos impactos causados pela execução da obra. A proposta apresentada pela perícia técnica era de se criar a UC ao lado da Serra da Confusão do Rio Preto, devido aos impactos ambientais que a obra estava causando naquele local.

Diante do laudo apresentado, os servidores da $2^{\mathrm{a}}$ Promotoria de Justiça de Quirinópolis oficiaram ao prefeito de Quirinópolis da época, concedendo-lhe o prazo de 10 dias para posicionar-se a respeito da criação da UC. Diante da inércia do município, o Ministério Público, representado pelos servidores da 2a Promotoria de Justiça de Quirinópolis, ajuizou Ação Civil Pública com pedido liminar para paralisação da obra na estrada vicinal da Serra da Confusão do Rio Preto, obtendo decisão favorável neste sentido. Com a paralisação da obra o prefeito municipal, então, concordou em firmar o TAC com o Ministério Público do Estado de Goiás. Através desse TAC finalmente a UC de Proteção Integral seria criada.

Apesar da proposta dos técnicos para a criação da UC ser na Serra da Confusão do Rio Preto, os representantes do Ministério Público do Estado de Goiás não são obrigados a acatar tal indicação. Dessa forma, os representantes do Ministério Público e do Poder Executivo de Quirinópolis decidiram que a criação da UC seria na Serra da Fortaleza. Dessa forma, em 2015 a criação da UC RVSSF foi formalizada legalmente, conforme a Lei n. 9.985/2000, a qual estabelece critérios e normas para a criação, implantação e gestão das unidades de conservação (Brasil, 2000).

A UC recebeu o nome Refúgio de Vida Silvestre Serra da Fortaleza. REVIS é uma categoria de UC de Proteção Integral definida pelo SNUC (MMA, 2019). O nome Serra da Fortaleza refere-se à localização da área da UC na Serra da Fortaleza. Vale ressaltar que no Brasil existem 698 UC's de Proteção Integral, sendo apenas 62 na categoria REVIS e destes apenas oito são municipais (CNUC/MMA, 2018). A UC RVSSF é a primeira nesta categoria para o estado de Goiás.

Em termos legais a área da UC pertence a um grupo de proprietários rurais como reserva legal extra propriedade de seus imóveis rurais. Entretanto, a gestão da UC RVSSF é de responsabilidade do Poder Executivo Municipal, conforme o estabelecido pela Constituição Federal, no Art. 225 (Brasil, 1998).

\section{Aspectos envolvidos na escolha do local da Unidade de Conservação}

A decisão de criar a UC na Serra da Fortaleza foi favorável para o Poder Executivo, pois a área já estava à disposição do Poder Público desde o acordo firmado com os proprietários rurais para o cumprimento do estabelecido no TAC. Logo, o gestor do Poder Executivo de Quirinópolis não teve que destinar recursos para comprar uma área destinada para criação da UC. Outro aspecto relevante é o de que a UC também deveria ser criada dentro da Bacia hidrográfica do município, critério que a área na Serra da Fortaleza atende.

Neste viés, os aspectos legais e ambientais que subsidiaram a importância de se criar a UC na Serra da Fortaleza foram consolidados pela necessidade de proteger os poucos remanescentes que abrigam a biodiversidade do Cerrado em Quirinópolis. De acordo com a Lei do SNUC, no Art. 22, §2: "a criação de uma unidade de conservação deve ser precedida de estudos técnicos e de consulta pública que permitam identificar a localização, a dimensão e os limites mais adequados para a unidade, conforme se dispuser em regulamento" (Brasil, 2000). Assim, a primeira etapa na criação da UC foi a elaboração de um estudo técnico o qual corroborou a importância ecológica da criação de uma UC na área da Serra da Fortaleza. Foram responsáveis pela elaboração deste documento os professores e acadêmicos do Curso de Ciências Biológicas da Universidade Estadual de Goiás (UEG), Câmpus Sudoeste, sede Quirinópolis, técnicos da Semad Goiás e da empresa Oliveira Geoambiental Ltda.

De acordo com a análise dos dados que integram o relatório, a área escolhida para UC, em razão de sua extensão e estado de conservação, abrange características naturais relevantes. No estudo para criação da UC todos os grupos taxonômicos inventariados corroboraram que o local abriga espécies ameaçadas, nas categorias: vulneráveis, em perigo, e também criticamente em perigo (Resende et al., 2015). No local existem animais de grande porte os quais podem estar ameaçados pela 
caça. Os pesquisadores que participaram do diagnóstico ambiental para a criação da UC relataram ter encontrado e retirado armadilhas de caça do local.

A UC abriga também espécies de ocorrência pouco amostradas no país, sendo várias delas os primeiros registros de ocorrência para Goiás (Resende et al., 2015). Adiciona-se como relevância ambiental a existência de corredores ecológicos que conectam a área da UC a outros remanescentes de vegetação nativa da Serra da Fortaleza, os quais são de fundamental importância para espécies que habitam a região e necessitam de grandes áreas para o forrageamento e manutenção de suas populações. Logo, a criação da UC RVSSF constituiu uma ação e estratégia conservacionista para a biodiversidade do Sul Goiano e para o Cerrado.

Além disso, outro aspecto relevante para criação da UC RVSSF é que não havia necessidade de desapropriação da área. E ainda, o diagnóstico ambiental demonstrou que a área é de fundamental importância para o abastecimento hídrico da região. Existem no local cursos de água que integram e circundam a UC e fazem parte do Ribeirão Fortaleza. Este ribeirão deságua no Rio São Francisco que em sua sequência deságua no Rio Paranaíba. Por fim, todos os elementos citados, justificam a criação da UC RVSSF, devido ao seu alto potencial para a conservação o que assegura a manutenção e o suporte dos serviços ecológicos e ambientais essenciais para a biodiversidade e a sociedade, além de criar importantes oportunidades para ações de ensino, pesquisa, extensão, ecoturismo, de educação ambiental e geração de emprego e renda para a população local.

\section{Etapas da formalização legal da Unidade de Conservação}

A criação de uma UC está prevista na lei do SNUC, Lei 9985/2000. Todas as etapas previstas para a criação e implantação da UC ocorrem nas esferas administrativas (Brasil, 2000; MMA, 2019).

No caso específico de Quirinópolis, como a criação da UC RVSSF se deu em razão de compromisso ajustado entre Ministério Público do Estado de Goiás e o Poder Executivo, houve no âmbito ministerial um procedimento administrativo para acompanhar as fases de implantação da referida Unidade. Até o momento já foram superadas as seguintes etapas: A- Estudo Técnico (tem a finalidade de identificar os aspectos naturais e culturais da área escolhida para a UC e seu entorno, determinar sua categoria e limites. Para sua realização existem diretrizes específicas a serem seguidas, dispostas na Resolução do Conselho Estadual de Meio Ambiente (CEMAm) nº 071/2007 (Resende et al., 2015)); B- Consulta Pública (consiste numa reunião com a população local e partes interessadas, para apresentar os dados obtidos no Estudo Técnico corroborando a relevância de determinada área ser convertida em UC; o convite deve informar data, local e hora da sua realização mediante ampla divulgação e publicação no Diário Oficial da União de aviso de consulta pública; essa ação também possui diretrizes detalhadas na Resolução CEMAm nº 058/2006 (CEMAM, 2006; MMA, 2019; Moraes et al., 2020)); C- Criação da UC pela Instituição da Lei Municipal n. 3173, de 12 de agosto de 2015 (esta etapa abrange a Instituição legal de uma UC, a qual consiste no ato legal de criação da unidade de conservação, com a publicação de Lei ou Decreto em Diário Oficial da esfera administrativa criadora (Resende et al., 2015)); e D- Cadastro da UC RVSSF junto ao Sistema Estadual de Unidades de Conservação - SEUC (esta etapa foi realizada e agora este órgão deverá realizar o cadastro da unidade no Ministério do Meio Ambiente). A próxima etapa a ser realizada é a elaboração do Plano de Manejo da UC.

As UC's de Proteção Integral têm um conjunto de diretrizes a serem seguidas para que o local seja concretamente mantenedor das áreas de vegetação nativa conservadas. Dentre essas diretrizes destacam-se o fato de apenas se permitirem ações de uso indireto e primar pela finalidade básica da UC em preservar ecossistemas naturais de grande relevância ecológica e beleza cênica (Brasil, 2000; Moraes et al., 2020). Para que essas diretrizes sejam seguidas e a UC RVSSF seja plenamente instituída deve haver plano de manejo, equipe treinada, infraestrutura, monitoramento, entre outros aspectos essenciais à conservação do local. 
De acordo com a Lei no 14.247/2002 o Plano de manejo é um documento técnico norteado pelos objetivos gerais de uma unidade de conservação, no qual se estabelecem o zoneamento e as normas que devem presidir o uso da área e o manejo dos recursos naturais, inclusive a implantação das estruturas físicas necessárias à gestão da unidade (Goiás, 2002). Este diagnóstico ambiental deve ser elaborado após a criação da UC e abrange estudos amplos, com detalhamentos e período maior de coletas de dados. Com isso é possível obter um conhecimento mais completo da área da UC e propor as estratégias de ações conservacionistas e de gestão no local.

Vale ressaltar que uma das dificuldades em criar e gerir a UC RVSSF se deve ao fato de que a prefeitura dispõe de poucos funcionários na área ambiental. Neste sentido, esforços futuros do Poder executivo deverão ser revertidos em prol de ampliar a equipe da prefeitura que atua especificamente nas ações que afetam diretamente a proteção da UC RVSSF.

\section{Descrição da elaboração do Estudo Técnico}

O Estudo Técnico objetiva levantar e apresentar um diagnóstico ambiental, socioeconômico e fundiário da área onde se pretende implantar a UC. Ele abrange a caracterização da área, indicação da denominação, categoria de manejo, objetivos, limites, área da unidade e o órgão responsável por sua administração de acordo com as indicações das Leis nº 9.985/2000, 14.247/2002, Decreto nº. 4.340/2002 e Resolução nº. 079/2007 do CEMAm de Goiás (Resende et al., 2015).

O grupo de trabalho para elaboração do Estudo Técnico foi técnicos da Secretaria de Agricultura e Meio Ambiente e, da empresa Oliveira Geoambiental Ltda. e docentes e acadêmicos do Curso de Ciências Biológicas da UEG, Câmpus Quirinópolis.

O Estudo Técnico foi realizado em áreas com três abrangências: onde foi instalada a UC RVSSF, no seu entorno, considerando a influência direta nesta UC, e na região na qual esta UC se encontra inserida. As informações foram obtidas por meio da coleta de dados primários, coletados em campo; e dados secundários, através de consultas bibliográficas, visitas à comunidade e instituições com atuação local (Resende et al., 2015).

O Estudo Técnico também abrangeu um levantamento bibliográfico sobre a legislação e os trabalhos existentes, abordando questões relacionados ao meio físico, socioeconômico, fundiário e histórico da região em questão.

As primeiras coletas na UC RVSSF abrangeram um conjunto de dados para reconhecimento e caracterização prévia da área como: delimitação preliminar da área com auxílio de GPS; verificação dos limites; levantamento preliminar da situação fundiária; identificação de áreas naturais e culturais relevantes; levantamento de dados sobre o meio físico; identificação e caracterização quanto à localização, acesso, relevo, hidrografia, áreas suscetíveis à erosão, inundação e assoreamento (Resende et al., 2015).

Paralelamente às coletas de dados dos fatores abióticos ocorreu o levantamento rápido da fauna e flora. Com o volume de dados amostrados foi realizado o geoprocessamento, confecção do mapa da área da UC, a análise e interpretação dos dados abióticos e bióticos, os quais resultaram na elaboração do relatório inerente ao Estudo Técnico (Resende et al., 2015).

O Estudo Técnico foi apresentado na Consulta Pública para criação da UC RVSSF, realizada em 21/07/15, no auditório da Câmara Municipal de Quirinópolis. Neste ato público estiveram presentes, além de munícipes, os técnicos envolvidos na elaboração do Estudo Técnico e representantes dos Poderes Executivo e Legislativo.

\section{Envolvimento e opinião pessoal dos entrevistados com relação à criação da UC RVSSF}

Todas as questões do questionário foram respondidas pelos entrevistados, com exceção de um entrevistado que declarou, em apenas uma pergunta, não ter conhecimento sobre a mesma.

Entre os entrevistados quatro deles foram questionados sobre a participação dele ou dela na criação da UC RVSSF e a importância dessa UC. O entrevistado que não foi incluído nesse questionamento não vivenciou essa etapa de criação da UC. A 
síntese sobre o teor das respostas está no Quadro 2. De acordo com as respostas é possível perceber as diferentes contribuições, diante da especificidade profissional de cada entrevistado, que culminaram na criação da UC RVSSF. Todos comungam da mesma opinião quanto a importância da UC RVSSF no tocante à conservação de remanescentes de Cerrado, diante do cenário de degradação do sul goiano.

O entrevistado 1 foi questionado se a criação da UC RVSSF foi resultante da solicitação da ONG Associação Galeatus no tocante a destinar a compensação ambiental das Usinas implantadas no município de Quirinópolis para UC. O mesmo entrevistado deixou claro que não fora exigido por parte do órgão competente para aprovação dos EIA-RIMA (Estudos de Impacto Ambiental- Relatório de Impacto Ambiental), apresentados pelas duas usinas, a criação de uma UC como medida compensatória. No entanto, se houvesse exigência para que as usinas ficassem obrigadas à criação de uma UC como medida compensatória pelos impactos causados por suas atividades no município, somente poderiam criar uma Reserva Particular do Patrimônio Natural - RPPN - e não uma UC de Proteção Integral, como a que foi efetivamente criada em Quirinópolis, na modalidade Refúgio de Vida Silvestre. Isto porque, todas as UC previstas pela Lei do SNUC - Lei 9985/2000 -, somente podem ser criadas pelo Poder Público, com exceção da RPPN, que é a única categoria de UC criada por particular e em área privada, por ato voluntário do proprietário. Dessa forma, não há qualquer conexão entre a proposta feita, em 2006, pela ONG Galeatus às usinas com a criação da UC RVSSF.

Quadro 2. Síntese das respostas dos entrevistados inerente ao questionamento sobre qual foi a contribuição dele (a) na criação da UC REVIS Serra da Fortaleza e a importância da UC, Quirinópolis, GO.

\begin{tabular}{|c|c|c|}
\hline Entrevistado & Participação na criação da UC & Importância da UC \\
\hline 1 & $\begin{array}{l}\text { Idealizou a criação da UC REVIS Serra da Fortaleza e lutou junto ao Ministério } \\
\text { Público desde } 2009 \text { e estabeleceu parcerias que tornaram possível a concretização } \\
\text { dessa UC. Segundo este entrevistado, os parceiros fundamentais, sem os quais } \\
\text { seria impossível a criação desse importante instrumento de gestão ambiental, se } \\
\text { destacam os proprietários rurais que disponibilizaram suas reservas legais para a } \\
\text { criação da UC, o Município de Quirinópolis, por meio dos prefeitos municipais } \\
\text { das duas gestões no período de criação da UC e a UEG, Câmpus Quirinópolis. }\end{array}$ & $\begin{array}{l}\text { Dentre os instrumentos de política ambiental para } \\
\text { conservação do Cerrado, a UC constitui a forma mais } \\
\text { eficiente de conservação dos recursos naturais. É } \\
\text { eficiente mecanismo de amortecimento dos prejuízos } \\
\text { causados à biota em consequência do avanço da } \\
\text { fronteira agrícola e da ocupação urbana no município }\end{array}$ \\
\hline 2 & $\begin{array}{l}\text { Participou do diagnóstico ambiental com o levantamento de aves em } \\
\text { campo e escreveu um texto sobre esse grupo. Auxiliou na organização da } \\
\text { documentação, audiência pública, elaboração da lei de criaçãa e do cadastro da } \\
\text { UC junto ao SEUC. Depois da criação da UC tem realizado pesquisa na área sobre } \\
\text { as respostas fisiológicas das aves à fragmentação. }\end{array}$ & $\begin{array}{l}\text { Tem importância em conservar remanescentes } \\
\text { de vegetação nativa, a fauna e flora da região. Também } \\
\text { é um local importante para pesquisas e atividades de } \\
\text { educação ambiental. }\end{array}$ \\
\hline 3 & $\begin{array}{l}\text { Fez contribuições no diagnóstico ambiental como conhecedor do meio ambiente e } \\
\text { da geografia. Participou das questões que envolviam o Poder Executivo e a } \\
\text { SECIMA, propiciando o intercâmbio de informações entre esses dois órgãos. }\end{array}$ & $\begin{array}{l}\text { Ressalta que a UC REVIS Serra da Fortaleza é um } \\
\text { legado nacional, pois essa UC está entre as poucas UC } \\
\text { de Refúgio de Vida Silvestre no país gerida por um } \\
\text { município. }\end{array}$ \\
\hline 4 & $\begin{array}{l}\text { Participou do estudo ecológico rápido, através da elaboração do inventário de } \\
\text { mamíferos não-voadores. Participou de duas etapas do diagnóstico da fauna e } \\
\text { flora. Ainda não desenvolveu nenhuma pesquisa depois da criação da UC. }\end{array}$ & $\begin{array}{l}\text { Diz que toda a porção sul do estado de Goiás encontra- } \\
\text { se fortemente fragmentada, e o município de } \\
\text { Quirinópolis não é exceção. Dessa forma, a criação de } \\
\text { uma UC contribui na preservação de uma parte dessa } \\
\text { paisagem antropizada. }\end{array}$ \\
\hline
\end{tabular}

Fonte: Autores.

Depois de ter ocorrido a regularização das áreas de reservas legal entre os produtores e o Ministério Público e a criação da UC RVSSF, a responsabilidade pelo conjunto de ações conservacionistas do local passou a ser do Poder Executivo. Esse conjunto de ações deve estar previsto no plano de manejo, conforme disposição contida na Constituição Federal, artigo 225, parágrafo primeiro (Resende et al., 2015).

Segundo o entrevistado 1 já existe um Conselho Consultivo que promove a gestão da UC RVSSF. Já segundo o entrevistado 5 a UC RVSSF não possui um Conselho Consultivo. Para ele, o Conselho Municipal de Meio Ambiente (COMMAM) é o órgão gestor da UC RVSSF até a criação do Conselho Consultivo, que se dará durante o andamento da elaboração do Plano de Manejo. O Conselho Consultivo decide sobre assuntos relacionados à forma de funcionamento da UC, 
prevista em seu Regimento Interno. Atua de acordo com as competências definidas no Decreto n ${ }^{\circ}$ 4.340/2002 (Abirached et al, 2014).

Além dos inúmeros benefícios ecológicos já mencionados, houve também um benefício econômico para o município de Quirinópolis resultante da criação da UC RVSSF. Segundo o entrevistado 3 com a criação da UC o município passou a receber o ICMS ecológico, verba mensal de aproximadamente R\$200.000,00 (duzentos mil reais). Em 2007, o Estado de Goiás aprovou a Emenda Constitucional no 40 que prevê a destinação de 5\% dos recursos para o ICMS Ecológico. Esta Emenda culminou na aprovação da Lei Complementar n 90/2011, a qual instituiu o ICMS Ecológico no estado. Neste viés, entre as exigências para os municípios serem contemplados com os recursos do ICMS Ecológico em Goiás está a de possuir em seu território unidades de conservação ambiental, ou que sejam diretamente influenciados por elas (Goiás, 2011).

Em 10 de setembro de 2018 foi realizado um evento para formalizar a assinatura do convênio intitulado "Plano de Manejo Ambiental da Unidade de Conservação Refúgio da Vida Silvestre Serra da Fortaleza”, entre o Poder Executivo e a UEG, Câmpus Sudoeste, Sede Quirinópolis. O convênio abrange uma cooperação técnica entre docentes e acadêmicos da UEG e o Poder Executivo. Nesta cooperação o Poder Executivo se responsabiliza pela construção de uma Estação de Pesquisa na UC RVSSF e, em contrapartida, os pesquisadores da UEG, realizarão os trabalhos técnicos no âmbito da elaboração de parte do referido Plano de Manejo. A partir da assinatura do convênio o prazo estabelecido seria de 24 meses para a conclusão do Plano de Manejo. Neste período, o uso indireto da UC não pode ser efetivado até a conclusão do Plano de Manejo. Entretanto, o Plano de Manejo ainda se encontra em fase de elaboração. Vale ressaltar, que a UC RVSSF está sujeita a normas e regras especiais que serão estabelecidas no Plano de Manejo. Este documento abrangerá um conjunto de estratégias e ações direcionadas à manutenção do equilíbrio ecológico, o que, consequentemente, irá assegurar a permanência da biodiversidade local.

A elaboração do Plano de Manejo da UC RVSSF deverá contar com o apoio de professores e acadêmicos do Curso de Ciências Biológicas, Geografia e História da Universidade Estadual de Goiás, Câmpus Sudoeste, Sede Quirinópolis, e técnicos da Semad Goiás e da Agência Goiana de Assistência Técnica, Extensão Rural e Pesquisa Agropecuária - EMATER.

No convênio firmado entre o poder executivo e a UEG uma das ações a serem implementadas é a construção da Estação de Pesquisa na UC RVSSF, a qual objetiva servir como local de alojamento e apoio aos pesquisadores durante a coleta de dados para elaboração do Plano de Manejo, bem como para futuras pesquisas a serem desenvolvidas no local. Também deverá ser o local de recepção de visitantes, principalmente as comunidades escolares com atividades de educação ambiental e aqueles ligados ao ecoturismo (segmento da atividade turística que usa de forma sustentável os patrimônios natural e cultural, incentivando sua conservação e buscando a formação de uma consciência ambiental por meio da compreensão do meio ambiente, promovendo, assim, o bem-estar da população que reside nestes locais (Perdigão et al., 2018)), e para abrigar a administração da UC RVSSF. Esta obra ainda não foi finalizada até o momento, o que tem dificultado as pesquisas quanto à amostragem da biodiversidade para integrar o Plano de Manejo.

A UC RVSSF conta com monitoramento esporádico abrangendo visitas in loco quando há alguma demanda ou quando ocorre alguma denúncia e ou relato de algum fato que deve ser averiguado. Este monitoramento é realizado por servidores da Secretaria Municipal de Meio Ambiente e Recursos Hídricos.

\section{Considerações Finais}

Pelo processo histórico aqui descrito podemos inferir que a criação da UC RVSSF foi devida a um conjunto de ações mobilizadas por um grupo de proprietários de imóveis rurais ao destinar a reserva legal conjuntamente para uma área como reserva legal extra propriedade; pela contínua ação dos servidores do Ministério Público junto ao Poder Executivo para a efetivação do compromisso firmado no TAC e a contribuição de pesquisadores da UEG, Câmpus Sudoeste, Sede Quirinópolis, 
juntamente com os servidores da Secretaria Municipal de Meio Ambiente e Recursos Hídricos. Os procedimentos para criação seguiram os preceitos subsidiados pela legislação ambiental vigente. Além dos aspectos ecológicos e conservacionistas, a relevância da criação desta UC RVSSF em Quirinópolis ainda se torna maior porque é o primeiro espaço de conservação em Goiás na categoria Refúgio de Vida Silvestre. Esta UC consiste em uma importante estratégia em prol de assegurar a manutenção do recurso hídrico e de uma rica biodiversidade de um dos patrimônios ecológicos mais ameaçados do mundo, o domínio fitogeográfico do Cerrado.

Além da manutenção da biodiversidade e ecossistemas locais, a UC RVSSF tem relevante importância como espaço para projetos de pesquisas científicas e de educação ambiental, o que também irá contribuir para a formação de crianças, jovens e adultos pautados em uma concepção ecológica e sustentável, além de contribuir para o ecoturismo. Entretanto, várias ações ainda precisam ser efetivadas, sendo as principais delas a elaboração e implementação do Plano de Manejo, para que efetivamente as funções ecológicas, sociais e culturais sejam contempladas no ambiente da UC RVSSF.

\section{Agradecimentos}

Agradecemos a todos que contribuíram para criação da UC RVSSF.

\section{Referências}

Abirached, C. F. A., Mendonça, F. C., Virginia, L. L. \& Lasmar, T. V. (2014). Guia - Conselhos Gestores de Unidades de Conservação Ambientais. ICMBio, Apoio: GIZ/GOPA.

Brasil. (1988). Constituição da República Federativa do Brasil. Senado Federal: Centro Gráfico.

Brasil. (2000). Lei Federal nº 9.985, de 18 de julho de 2000. Institui o Sistema Nacional de Unidades de Conservação da Natureza (SNUC).

Brasil. (2001). Lei n ${ }^{\circ} 10.267$, de 28 de agosto de 2001. Altera dispositivos das Leis nos 4.947, de 6 de abril de 1966, 5.868, de 12 de dezembro de 1972, 6.015, de 31 de dezembro de 1973, 6.739, de 5 de dezembro de 1979, 9.393, de 19 de dezembro de 1996, e dá outras providências.

Brasil. (2002). Decreto Federal n ${ }^{\circ}$ 4.340, de 13 de dezembro de 2002. Regulamenta os arts. 22, 24, 25, 26, 27, 29, 30, 33, 36, 41, 42, 47, 48 e 55 da Lei ${ }^{\circ}$ 9.985, de 18 de julho de 2000, bem como os arts. 15, 17, 18 e 20, no que concerne aos conselhos das unidades de conservação.

Bueno, V. R., Morais, I. L. de, Nakajima, J. N. (2019). Isostigma resupinatum (Coreopsideae, Asteraceae), a new species from Central Plateau, Goiás State, Brazil. Phytotaxa, 408 (3), 227 - 232.

CEMAM (Conselho Estadual do Meio Ambiente). (2006). Resolução nº 058 de 2006. Dispõe sobre o processo de consultas públicas para criação de unidades de conservação no Estado de Goiás.

CNUC/MMA. (2018) Tabela Consolidada das Unidades de Conservação. 2018. http://www.mma.gov.br/images/arquivo/80229/CNUC_JUL18\%20\%20B_Cat.pdf.

CNS (Conselho Nacional de Saúde). (2012). Resolução no 466, de 12 de dezembro de 2012. <https://conselho.saude.gov.br/resolucoes/2012/Reso466.pdf>. 13.Jul.2018.

CNS (Conselho Nacional de Saúde). (2016). Resolução n $\mathrm{n}^{\circ}$ 510, de 07 de abril de 2016. <http://conselho.saude.gov.br/resolucoes/2016/Reso510.pdf>. 14.Mai.2018.

Galinkin, M. (2003). Geogoiás. Galinkin, M. (Ed.). Agência Ambiental do Estado de Goiás. Fundação CEBRAC, Goiânia: PNUMA: SEMARH - GO.

Ganem, R. S. Conservação da Biodiversidade: legislação e políticas públicas. Brasília: Câmara dos Deputados: Edições Câmara, 2010. p. 437 - (Série memória e análise de leis, n. 2).

Garbelini, S. M. Manual prático de Unidades de Conservação. (2011). Ministério Público do Estado de Goiás. Goiânia: ESMP.

Goiás. (2002). Lei Estadual n 14.247, de 29 de julho de 2002. Esta lei institui o Sistema Estadual de Unidades de Conservação no Estado de Goiás.

Goiás. (2003). Decreto Estadual nº 5.806, de 21 de julho de 2003. Institui a Câmara Superior das Unidades de Conservação do Estado de Goiás.

Goiás. (2011). Lei Complementar n ${ }^{\circ}$ 90, de 22 de dezembro de 2011. Regulamenta o disposto no inciso III do $\S 1^{\circ}$ do art. 107 da Constituição Estadual, acrescido pela Emenda Constitucional n 40, de 30 de maio de 2007.

Goiás. (2013). Lei nº 18.104, de 18 de julho de 2013. Dispõe sobre a proteção da vegetação nativa, institui a nova Política Florestal do Estado de Goiás e dá outras providências.

Goiás. (2017). Decreto Estadual n 9.023, de 11 de agosto de 2017. Cria a Estação Ecológica Chapada de Nova Roma e dá outras providências. 
IBGE (Instituto Brasileiro de Geografia e Estatística). (2019). IBGE Cidades: Quirinópolis, GO. https://cidades.ibge.gov.br/brasil/go/quirinopolis.

ICMBio (Instituto Chico Mendes de Conservação da Biodiversidade). (2009). Sistema Nacional de Unidades de Conservação. Série: Legislação ICMBio, v. 1. Incra (Instituto Nacional de Colonização e Reforma Agrária). (2018). Norma de Execução INCRA/DF nº 02/2018.

Macarthur, R. \& Wilson, E.O. (1963). An equilibrium theory of insular zoogeography. Evolution, 17, 373 - 387.

Manzini, E. J. (1991). A entrevista na pesquisa social. Didática, 27, 149-158.

MMA (Ministério do Meio Ambiente). (2019). Roteiro para Criação de Unidades de Conservação Municipais. Brasília: Ministério do Meio Ambiente, Secretaria de Biodiversidade, Departametno de Áreas protegidas.

Moraes, L. A., Araújo, M. F. V. \& Conceição, G. M. da. (2020). O processo de criação e implantação do Parque Estadual Cânion rio Poti, Buriti dos Montes, Piauí. Research, Society and Development, 9 (9), e71996486.

Morais, I. L. de., Rizzo, C. D., Brandelero, S. M. \& Hannibal, W. (2021). Eficácia de placas educativas no descarte de resíduos sólidos urbanos e à não alimentação do sagui-de-trufo-preto (Callithrix penicillata). Research, Society and Development, 10 (13), e300101321463.

Morais, I. L. de, Zambiasi, R. M., Aguiar, D. S., Silva, A. V. \& Neto, J. L. (2017). Flora da Unidade de Conervação Refúgio de Vida Silvestre Serra da Fortaleza, Quirinópolis, Sul de Goiás. In: Hannibal, W., et al. Biodiversidade, Manejo e Conservação do Sul de Goiás. 1. ed. Jundiaí: Paco.

Morillo, G., Morais, I. L. de, Farinaccio, M. A. (2017).Matelea atrolingua, una nueva Apocynaceae cuyos lóbulos corolinos semejan la lengua de un mamífero muerto. Iheringia Série Botânica, 72 (3), 319-324.

Perdigão, G. S., Cordeiro, J., Calazans, G. M., Nascimento, F. D., Ferreira, D. L. G., Brandão, J. M. S. \& Guimarães, J. C. S. Contribuições da geologia para o desenvolvimento do ecoturismo na comunidade de Cabeça de Boi, Itambé do Mato Dentro (MG). Research, Society and Development, 7 (5), e475149, 2018.

Pereira, A. S., Shitsuka, D. M., Parreira, F. J. \& Shitsuka, R. (2018). Metodologia da pesquisa científica. UFSM. https://repositorio.ufsm.br/bitstream/handle/1/15824/Lic_Computacao_Metodologia-Pesquisa-Cientifica.pdf?sequence=1 .

Resende, I. L. M., Teixeira, L. M., Hannibal, W., Rossi, R. F., Oliveira, M. S., Carvalho, S. R. \& Paula, V. L. (2015). Estudo técnico para criação de unidade de conservação na categoria refúgio de vida silvestre - RVS “Serra da Fortaleza” no municipio de Quirinópolis/GO. Prefeitura de Quirinópolis, Quirinópolis, GO.

Rocha, M. B., Rocha, T., Miceli, B. \& Costa, P. M. M. da. (2019). Análise do Perfil dos Visitantes em uma Unidade de Conservação: o caso do Parque Nacional da Tijuca. Research, Society and Development, 8 (2), e4982775.

Sano, E. E., Rosa, R., Brito, J. L. S. \& Ferreira, L. G. (2007). Mapeamento de cobertura vegetal do bioma Cerrado - estratégias e resultados. Documentos/Embrapa Cerrados, 190, 1-30.

Salmona, Y. B., Ribeiro, F. F. \& Matricardi, E. A.T. (2014). Parques “no papel” conservam? O caso do Parque dos Pireneus em Goiás. Bol. Goia. Geogr., 34 (2), 295-310.

Salomão, P. E. A., Barbosa, L. C. \& Cordeiro, I. J. M. (2020). Recuperação de áreas degradadas por pastagem: uma breve revisão. Research, Society and Development, 9 (2), e57922057.

Semad (Secretaria de Estado de Meio Ambiente e Desenvolvimento Sustentável). (2021). https://www.meioambiente.go.gov.br/acesso-a-informacao/118meio-ambiente/unidades-de-conserva\%C3\%A7\%C3\%A3o/1082-unidade-de-conserva\%C3\%A7\%C3\%A3o-em-goias.html

Simões, L. L. (Coord.). (2008). Unidades de Conservação: conservando a vida, os bens e os serviços ambientais. WWF.

Viana, A. L., Silva, N. M. da, Silva, J. R. C. da, Lins Neto, N. F. A., Santos, R. M. S. \& Neves, R. K. R. (2020). Decrescimento, entropia e sustentabilidade: os limites do crescimento econômico. Research, Society and Development, 9 (12), e17091210999.

Yin, R. K. (2009). Case study research, design and methods (applied social research methods). Thousand Oaks. California: Sage Publications. 